\title{
How to Proceed in Helicobacter pylori-Positive Chronic Gastritis Refractory to First- and Second-Line Eradication Therapy
}

\author{
Dino Vaira ${ }^{a}$ Chiara Ricci $^{b} \quad$ Alberto Lanzini $^{b}$ Federico Perna ${ }^{a}$ \\ Antonio Romano ${ }^{a}$ Roberto Corinaldesi ${ }^{a}$ \\ ${ }^{a}$ Department of Internal Medicine and Gastroenterology, University of Bologna, Bologna, and \\ ${ }^{b}$ Gastroenterology Unit, University of Brescia, Brescia, Italy
}

\section{Key Words}

Helicobacter pylori infection $\cdot$ Chronic gastritis $\cdot$ Eradication therapy $\cdot$ Peptic ulcer disease

\begin{abstract}
Helicobacter pylori is a widespread disease causing most of the peptic ulcer diseases and low-grade mucosa-associated lymphoreticular tissue (MALT) lymphoma. Moreover, H. pylori is a proven environmental risk factor for gastric carcinoma and it has been recognized as a type 1 carcinogen factor. A combination of drugs has been proposed, using a proton pump inhibitor (PPI), amoxicillin, clarithromycin, metronidazole and tetracycline to treat the infection. Since 1996, according to the European guidelines, the first-line approach using PPI, amoxicillin and clarithromycin or metronidazole has been suggested. Seven days of quadruple therapy with PPI (or ranitidine), tetracycline, bismuth salts and metronidazole has been reserved as second-line treatment. To improve the eradication rate of the triple therapy, a different combination of the available antibiotics has been proposed, consisting of a 10-day sequential regimen. A second-line levofloxacin-amoxicillin-based triple therapy given for 10 days has been proposed, obtaining a high eradication rate, suggesting this regimen to be a suitable retreatment option in eradication failure. A third-line treatment with rifabutinbased regimen has been proposed.
\end{abstract}

Copyright $\odot 2007$ S. Karger AG, Basel
(C) 2007 S. Karger AG, Basel

0257-2753/07/0253-0203\$23.50/0

Fax +4161306 1234

E-Mail karger@karger.ch

www.karger.com
Accessible online at: www.karger.com/ddi
Helicobacter pylori infection is a cause of peptic ulcer disease, gastric mucosa-associated lymphoreticular tissue (MALT) lymphoma and gastric cancer [1]. Standard treatments for $H$. pylori that have been endorsed by US and European authorities rely on clarithromycin or metronidazole in conjunction with other antibiotics and acid inhibitors $[2,3]$. The prevalence of clarithromycin and metronidazole resistance has increased significantly in recent years and there has been a corresponding decline in the eradication rate for $H$. pylori [4]. Eradication rates in most Western countries have declined to unacceptable values with approximately $1 / 5$ patients failing eradication therapy [5]. A simple, short treatment regimen that would return eradication levels to the high values seen at the advent of $H$. pylori treatment is urgently needed [5]. Such a treatment regimen should have high efficacy against clarithromycin- and metronidazole-resistant strains of $H$. pylori as these strains are increasingly encountered in routine clinical practice.

Triple therapy with a proton pump inhibitor (PPI), clarithromycin, and either amoxicillin or metronidazole is the most popular treatment regimen to cure $H$. pylori infection among primary care physicians and gastroenterologists in the USA and Europe [6-8]. However, two double-blind, US multicenter studies recently found disappointingly low eradication rates with this regimen. In one study, $75.6 \%$ of 402 patients and in the other, $77.2 \%$ 
of 307 patients were cured of $H$. pylori infection following a 10 -day triple regimen $[9,10]$. Low eradication rates have also been reported with this regimen in Europe, and Australia and Asia [11].

A novel 10-day sequential therapy consisting of a 5day dual (PPI + amoxicillin) therapy followed by a 5-day triple (PPI, clarithromycin and tinidazole) therapy has had a good eradication success in unblended trials in adult and pediatric patients [12-14]. Recently, a doubleblind controlled trial against conventional therapy demonstrated that sequential therapy has high eradication rates, good tolerability, and high patient compliance [15].

The outcome of $H$. pylori therapy depends to a significant degree on compliance with the regimen and the presence of antibiotic resistance [16]. Clarithromycin resistance is a major problem in many Western countries, and its prevalence is $12.9 \%$ (varying from 6.1 to $14.5 \%$ ) in the USA, and as high as $24 \%$ in some European countries [17-19]. A systematic review of $H$. pylori therapy reported a 53\% decrease in eradication rates if clarithromycin resistance was present and a clarithromycin-containing regimen was used [16]. The reasons why the sequential regimen is more effective than the standard therapy on clarithromycin-resistant strains have been previously reported [20]. Briefly, the first course of sequential therapy is based on amoxicillin's ability to destroy the bacterial wall impairing the transmembrane efflux system which acts contrasting the intracellular clarithromycin entrapment in the resistant strains [20]. In agreement with previous studies, we suggest that the role of metronidazole resistance is less important for treatment success with clarithromycin-based triple therapy [21].

Cost is a major consideration in many countries. In Europe the cost of the sequential regimen is similar to that of the standard regimen making it an attractive alternative to current triple therapy. Tinidazole has recently become available in the USA and the cost of sequential therapy based on retail cost is lower than that of triple therapy. Sequential therapy may therefore be a reasonable alternative to standard therapy.

In 1996, the first European guidelines for H. pylori management were drawn up, and they were updated and substantially confirmed in 2000 [22]. The guidelines advise the use of a 7-day triple therapy, comprising a PPI (or ranitidine bismuth citrate), clarithromycin and amoxicillin or metronidazole as first-line therapy, whilst a 7day quadruple therapy (PPI, bismuth salts, tetracycline, and metronidazole) should be reserved for eradicationfailure patients.
Numerous clinical trials have been published since the last Maastricht conference. In susceptible strains the combination of PPI-clarithromycin-metronidazole is more successful than the combination of PPI-clarithromycin-amoxicillin. In the case of clarithromycin resistance alone, the eradication rates are also higher with PPI-clarithromycin-metronidazole than with PPI-clarithromycin-amoxicillin (50 vs. $18 \%$, respectively). In metronidazole resistance, when a PPI-clarithromycinmetronidazole regimen is used, there is a $25 \%$ decrease in eradication rate ( 72 vs. $97 \%$ ). The predicted eradication rates for the PPI-clarithromycin-metronidazole combination show a better efficacy than PPI-clarithromycinamoxicillin which is nullified only when metronidazole resistance reaches $40 \%$ [23].

\section{Second-Choice Therapy}

According to the recent Consensus report [23], bismuth-based quadruple therapy is a preferred option as second-choice therapy if not previously used. However, PPI triple therapies have been tested as second-choice treatment. Clarithromycin should not be used unless phenotypic or genotypic tests show that the strain is susceptible. The eradication rate obtained with the combination of PPI-amoxicillin-metronidazole was 89 and $64 \%$ for metronidazole-susceptible and -resistant strains, respectively. In a clinical trial using this combination as a second-choice therapy, the global eradication rate was $64 \%$.

Recently, a 10-day levofloxacin-based triple therapy has been shown to be safe and effective, achieving an eradication rate in almost $80 \%$ of the patients [24]. Similar results have been confirmed in two recent meta-analyses $[25,26]$.

\section{Third-Choice Therapy}

Two other classes of antibiotics have emerged in the treatment of $H$. pylori infection: a fluoroquinolone, levofloxacin, and a rifamycin, rifabutin. These antibiotics have been evaluated for the most part in first-choice therapies with PPI and amoxicillin rather than rescue therapies with a good success rate. However, rifabutin is an antibiotic which can select resistance among Mycobacterium, so it must be used cautiously. H. pylori resistance to rifabutin may occur but is rare. 
Culture for the management of $H$. pylori infection has been neglected for a long time, despite the fact that several studies have shown that higher eradication rates are obtained when antibiotics are chosen based on susceptibility testing versus choosing empirically. This may be a cost-effective approach. The high impact of clarithromycin resistance led to the proposal to perform culture and antimicrobial susceptibility testing when the resistance rate reaches $15-20 \%$. Culture and sensitivity may help in decision-making after failure of second-choice therapy. It has to be recommended that monitoring of primary antibiotic resistance be carried out in different regions in order to appreciate the risk of failure linked to antimicrobial resistance [23].

\section{References}

1 Suerbaum S, Michetti P: Helicobacter pylori infection. N Engl J Med 2002;347:11751186.

$\checkmark 2$ Malfertheiner P, Mégraud F, Morain CO, Hungin AP, Jones R, Axon A, et al: Current concepts in the management of Helicobacter pylori infection. The Maastricht 2-2000 Consensus Report. Aliment Pharmacol Ther 2002;16:167-180

3 Howden CW, Hunt RH: Guidelines for the management of Helicobacter pylori infection. Am J Gastroenterol 1998; 93:23302338.

4 Megraud F: H. pylori antibiotic resistance: prevalence, importance, and advances in testing. Gut 2004;53:1374-1384.

5 Vakil N: Helicobacter pylori treatment: a practical approach. Am J Gastroenterol 2006;101:497-499.

-6 Sharma VK, Howden CW: A national survey of primary care physicians' perceptions and practices related to Helicobater pylori infection. J Clin Gastroenterol 2004;38:326-331.

7 Maconi G, Tosetti C, Miroglio G, Parente F, Colombo E, Sainaghi M, Bianchi Porro G: Management of Helicobacter pylori-related gastrointestinal diseases by general practitioners in Italy. Aliment Pharmacol Ther 1999;13:1499-1504.

-8 Shirin H, Birkenfeld S, Shevah O, Levine A, Epstein J, Boaz M, et al: Application of Maastricht 2-2000 guidelines for the management of Helicobacter pylori among specialists and primary care physicians in Israel: Are we missing the malignant potential of Helicobacter pylori? J Clin Gastroenterol 2004;38: 322-325.

-9 Laine L, Fennerty MB, Osato M, Sugg J, Suchower L, Probst P, et al: Esomeprazolebased Helicobacter pylori eradication therapy and the effect of antibiotic resistance: results of three US multicenter, double-blind trials. Am J Gastroenterol 2000;95:33933398.
10 Vakil N, Lanza F, Schwartz H, Barth J: Seven-day therapy for Helicobacter pylori in the United States. Aliment Pharmacol Ther 2004;20:99-107.

11 Laheij RJ, Van Rossum LGM, Jansen JB, Straatman H, Verbeek AL: Evaluation of treatment regimens to cure Helicobacter pylori infection. A meta-analysis. Aliment Pharmacol Ther 1999;13:857-864.

12 Zullo A, Vaira D, Vakil N, Hassan C, Gatta L, Ricci C, et al: High eradication rates of $\mathrm{He}$ licobacter pylori with a new sequential treatment. Aliment Pharmacol Ther 2003;17: 719-726.

13 Zullo A, Gatta L, De Francesco V, Hassan C, Ricci C, Bernabucci V, et al: High rate of Helicobacter pylori eradication with sequential therapy in elderly patients with peptic ulcer: a prospective controlled study. Aliment Pharmacol Ther 2005;21:1419-1424.

14 Francavilla R, Lionetti E, Castellaneta SP, Magistà AM, Boscarelli G, Piscitelli D, et al: Improved efficacy of 10 -day sequential treatment for Helicobacter pylori eradication in children: a randomized trial. Gastroenterology 2005;129:1414-1419.

15 Vaira D, Zullo A, Vakil N, Gatta L, Ricci C, Pera F, et al: Sequential therapy versus triple therapy for Helicobacter pylori eradication: a randomized controlled trial. Ann Intern Med (submitted).

16 Houben M, van de Beek D, Hensen E, Craen AJ, Rauws EA, Tytgat GN: A systematic review of Helicobacter eradication therapy the impact of antimicrobial resistance on eradication rates. Aliment Pharmacol Ther 1999;13:1047-1055.

7 Osato M, Reddy R, Reddy SG, Penland RL, Malaty HM, Graham DY: Pattern of primary resistance of Helicobacter pylori to metronidazole or clarithromycin. Arch Intern Med 2001;161:1217-1220.
18 Duck WM, Sobel J, Pruckler J, Song Q, Swerdlow D, Friedman C, et al: Antimicrobial resistance incidence and risk factors among Helicobacter pylori-infected persons, United States. Emerg Infect Dis 2004;10: 1088-1094.

19 Koletzko S, Richy F, Bontems P, Crone J, Kalach N, Monteiro ML, et al: Prospective multicentre study on antibiotic resistance of $\mathrm{He}$ licobacter pylori strains obtained from children living in Europe. Gut 2006;55:18111816.

20 De Francesco V, Margiotta M, Zullo A, Hassan C, Troiani L, Burattini O, et al: Clarithromycin-resistant genotypes and eradication of Helicobacter pylori. Ann Intern Med 2006;144:94-100.

21 Graham DY: Therapy of Helicobacter pylori: current status and issues. Gastroenterology 2000;118:S2-S8.

22 Malfertheiner P, Megraud F, O’Morain C, et al: Current concepts in the management of Helicobacter pylori infection. The Maastricht 2-2000 Consensus Report. Aliment Pharmacol Ther 2002;16:167-180.

23 Malfertheiner P, Megraud F, O'Moran C, et al: Current concepts in the management of Helicobacter pylori infection. The Maastricht III Consensus Report. Gut 2007 in press.

24 Gatta L, Zullo A, Perna F, et al: A 10-day levofloxacin-based triple therapy in patients who failed two eradication courses. Aliment Pharmacol Ther 2005;22:45-49.

25 Saad R, Schoenfeld P, Kim HM, Chey WD: Levofloxacin-based triple therapy versus bismuth-based quadruple therapy for persistent $H$. pylori infection: a meta-analysis. Am J Gastroenterol 2006;101:488-496.

26 Gisbert J, et al: Systematic review and metaanalysis: levofloxacin-based rescue regimens after $H$. pylori treatment failure. Aliment Pharmacol Ther 2005;22:45-49. 